\title{
The ECO-COMPASS EU-China Project
}

\section{EMUS 2019}

\author{
JENS BACHMANN ${ }^{*}$, XIAOSU YI ${ }^{\dagger}$ \\ "German Aerospace Center (DLR) \\ Institute of Composite Structures and Adaptive Systems \\ Lilienthalplatz 7, 38108 Braunschweig, Germany \\ e-mail: jens.bachmann@dlr.de,www.dlr.de/en \\ ${ }^{\dagger}$ AVIC Beijing Institute of Aeronautical Materials (BIAM) /ACCT \\ University of Nottingham Ningbo China (UNNC) \\ e-mail: xiaosu.yi@nottingham.edu.cn
}

Key words: Composite, bio-based, flax, ramie, recycling, epoxy, honeycomb

\begin{abstract}
Fibre reinforced polymers are important materials used in aviation due to their excellent specific properties enabling the reduction of fuel consumption. For example, carbon fibre reinforced epoxy resins are used in fuselage and wing structures. Glass fibre reinforced phenolic resins are mainly used for the interior panels due to their low weight and favourable fire properties. All these composite materials used in aviation have one thing in common: they are man-made. Renewable materials like bio-fibres and bio-resins are under investigation for a long time for composites but they did not made it into modern aircraft in high amounts yet.

The project ECO-COMPASS under Horizon 2020 aims to bundle the knowledge of 17 partners from China and Europe to develop ecological improved composites for the use in aircraft interior and secondary structures [1]. Bio-based reinforcements, epoxy resin and sandwich cores are developed and improved for their application in aviation. Furthermore the use of recycled carbon fibres to increase the mechanical strength and multifunctional aspects of bio-composites are evaluated. In order to withstand the special stresses in aviation environment, protection technologies to mitigate the risks of fire, lightning and moisture uptake are under investigation. An adapted modelling and simulation will enable the optimization of the composite design. Electrical conductive composites for electromagnetic interference shielding and lightning strike protection are under investigation in ECOCOMPASS as well. The cooperation includes the exchange of knowledge and materials in order to optimize the development of ecological friendly composites.
\end{abstract}

\section{INTRODUCTION}

Lightweight structures made from composite materials have gained in importance due to 
their excellent mechanical properties combined with relatively low weight. Fibre Reinforced Polymers (FRP) enable the construction of lighter and more efficient aircrafts resulting in the reduction of fuel consumption and increased payloads. High performance composites like carbon-fibre reinforced plastics (CFRP) are used in primary structures of modern aircrafts like Airbus A350. Sandwich structures made of glass and aramid fibres with phenolic resins as matrix system find their application in the interior due to their low weight to stiffness ratio. But all these composite materials currently used in aviation have are synthetic and energy intensive in their production. Renewable materials like bio-based fibres and bio-based resin systems are under development and already used in other industries such as automotive. But they have not been introduced into a modern aircraft in noticeable amounts yet [1].

As safety is of primary importance in aviation, the lack of experience and confidence in the long-term performance and mechanical properties of composites made of renewable materials is still an obstacle for their usage. It is therefore at the moment out of scope to substitute high performance and safety-relevant composites like CFRP in primary structural parts of the aircraft, for example the fuselage frame and the outer wing box, with bio-based materials. On the other side, secondary structures and interior composites which are not stressed on such high levels offer possible areas of application. Examples for secondary structural parts are fairings and the landing gear doors. In the interior, cabin ceiling panels, sidewalls and floor panels are aims for the substitution of glass fibres and phenolic resins with ecological improved developments.

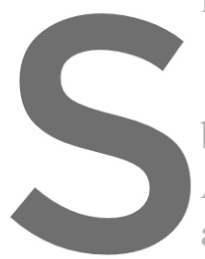

The composites uncter

based renewable resour

Added functionality

according to design 1
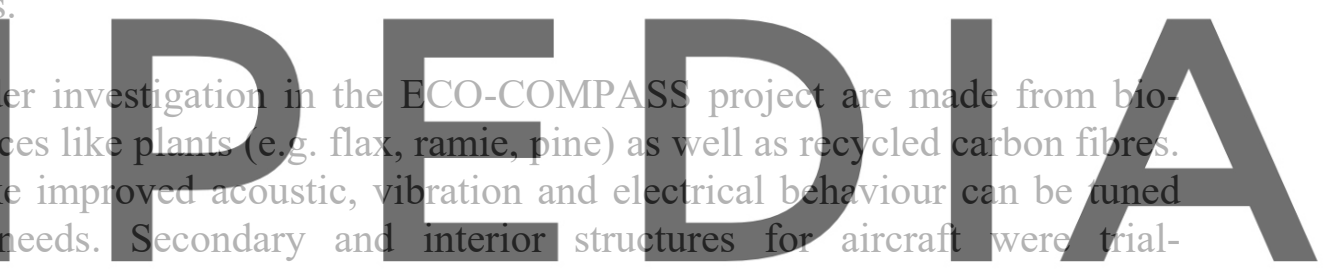

manufactured by using these material systems in different combinations thereof. The

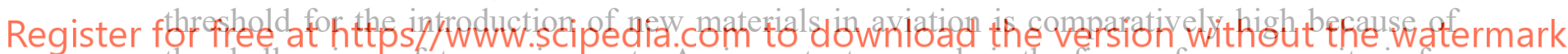
the challenging safety requirements. An important example is the fire performance criteria for materials used in the cabin environment. The following chapter gives an overview of materials and results obtained in the ECO-COMPASS EU-China international collaboration project.

\section{ECO-COMPOSITES}

Today, thermosets are the most important polymer family used in the aviation industry, due to their versatility, high performance and the wide span of applications they comprise. However, their petrochemical base and the difficulty of thermosets to be recycled, forces the industry to seek for feasible alternatives that can reduce the ecological footprint associated to their production. Bio-based resin systems are gaining in attraction in order to replace the traditionally used petrol-based resin systems. For aviation it is important to develop bio-based high-performance resins which are able to substitute the traditional epoxies for use in structural applications. A comprehensive review article of bio-based resin system available and under research has been prepared in the ECO-COMPASS project by Ramon et al [2]. Furthermore, rosin acid [3] and itaconic acid [4] have been synthesized, and formulated partly 
bio-based epoxy resins have been used to produce composites that can be compared to state of the art petrol-based epoxy resins [5]. Additionally, intrinsically flame retardant epoxy resin from renewable daidzein (diglycidyl ether of daidzein (DGED)) has been synthesized without addition of any flame-retardant element [6].

Further activities related to the bio-resins have focused on the introduction of nano fillers into the bio-based epoxy matrix and the preparation of specimens for mechanical and fire retardant testing. Silicon carbide nanoparticles, carbon nanotubes and nano clays have been selected as nano fillers to improve thermal, mechanical and conductive performance of the cured thermosets. High speed mixing followed by sonication has been used to disperse the previously functionalized nano fillers. After thermal and dispersion characterization, neat resin and nano modified resin tensile, compression and fire test specimens have been developed. Tensile and compressive tests have been performed to the neat resins showing values comparable to the currently used epoxies in this field.

A multitude of bio-based fibres is available on the world market. In Europe, flax and hemp fibres are the most common bast-fibres used to reinforce composites while ramie fibres that are grown in China are another suitable candidate. An important challenge of natural fibre reinforced polymers (NFRP) is their lack of strength compared to GFRP and especially CFRP. In theory, natural fibres can reach tensile strength of up to $1000 \mathrm{Mpa}$ while imperfections such as kink bands and the poor interfacial bonding properties between
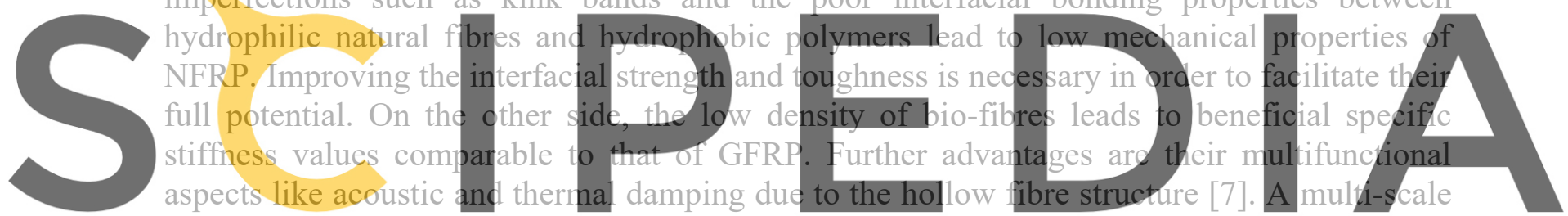

shear lag model was used to take the full advantages of the hierarchical structure of the NFRP

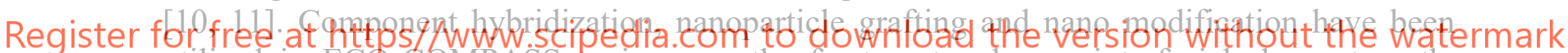
utilised in ECO-COMPASS to improve the fracture toughness, interfacial shear strength, tensile strength and modulus of bio-based fibres. Fire retardation and the anti-microbial performances could be improved as well [8], [9].

Another topic of ECO-COMPASS was the utilisation of recycled carbon fibres (rCF). Virgin carbon fibres ( $\mathrm{vCF}$ ) are very expensive due to their energy intensive production process. It is therefore of high importance to reuse these valuable fibres in order to save energy, raw materials and cost. Pyrolysed rCF are available in milled and chopped form. A restricted length and the removal of the fibre sizing are their main drawbacks compared to $\mathrm{vCF}[10]$. It is therefore at the moment not possible to give these "downcycled" fibres the same function as VCF. Therefore, an alternative way to improve the properties of pure NFRP by adding rCF has been assessed. Wet-laid [11] and carded [12] hybrid nonwoven of flax and rCF were produced on a small scale. Positive effects on the flexural properties on composite level can be observed by adding even small amounts of rCF. Furthermore, a honeycomb sandwich core was made of plant fibre hybrid paper containing $20 \%$ plant fibres and $80 \%$ chemical fibres (Green Honeycomb). The preparation process was similar to NOMEX® honeycomb and the developed material exhibits high strength and toughness in a small cell 
with low density.

In order for eco-composites to be a real alternative to synthetic composites, it is necessary to improve the existing knowledge about them, as well as to have analysis and simulation tools capable of representing accurately their structural performance. This will ensure that the structures designed with them comply with the required security, functionality and quality standards. The mechanical-numerical proposal for such purpose consists of the adaptation of generalized mixing theory and/or multiple scale homogenization theory [13], derived from the formulations for the classical composite material, and all these mechanical formulation within a framework provided by the genetic algorithms optimization [14]. So, the proposed procedure promises a detailed behaviour study of the whole composite, starting from each one's simple component behaviour. As an example, a ramie-woven sandwich laminate was analysed with a full numerical homogenization approach. The numerical procedure developed has been applied to improve the design of a cabin luggage bin (hatrack)

An important aspect for composites used in aircraft is the material multifunctionality. Examples are the electrical conductivity for structural composites in order to detect cracking [15], shield the electromagnetic interference and lightning strike protection (LSP). The Functionalized Interlayer Technology (FIT) was proposed in order to simultaneously increase the electrical conductivity and the interlaminar fracture toughness [16]. A coupled electricalthermal-pyrolytic model shows that the lightning strike damage is strongly governed by the
anisotropic electrical
was proposed to evalua
estimate the in-depth
going to quantitatively
laminates, supported by
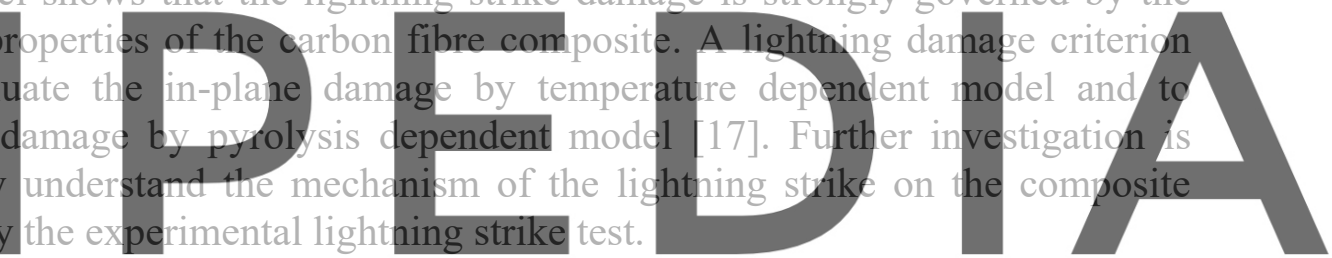

Register for free at hittps//www.scipedia.com to download the version without the watermark

Bio-based and multifunctional composites offer unique alternatives for aeronautical structures and can also expand state-of-the-art technologies. Based on the current results with the materials considered in ECO-COMPASS, partly bio-based epoxy resin systems have the highest potential for a successful application in aviation. Their properties approach the performance of the fully petrol-based epoxy resins used today. A case study from the ECOCOMPASS project demonstrates the manufacturing of an empennage side panel based on state of the art carbon fibre and partly bio-based epoxy resin including lightning strike protection. Improvements of resin properties such as conductivity and flammability with adapted flame retardants such as DOPO-MA and different nano fillers are under development. Green Honeycomb with small amount of natural fibre mixed with classic aramid fibre can be another technology with high potential for the introduction of bio-based materials in aviation composite structures.

Natural fibres such as ramie and flax have a high potential for weight reduction due to their low density and good damping properties. However, their long-term behaviour and mechanical properties need to be further improved. Potential technologies are under 
development, such as cellulose nanocrystal coating, plasma treatment and hybridization with recycled carbon fibres. Fire properties of NFRP with natural fibres and epoxy resin are a challenge the application in the cabin interior and baggage compartment. While flammability and toxicity are already under control for the combination of natural fibres and epoxy resin, the heat release and smoke density properties need further improvement.

Different numerical methods developed within ECO-COMPASS have been used to gain a better understanding of the performance of eco-composites, and can be used to predict the response of these materials when used in aerospace applications. A good design of an aerospace structure made with eco-composites will require accounting for the different aspects considered, from mechanical characterization to resistance to a lighting strike. The presented results highlight materials-enabled potential, and an alternative solution to reduce environmental impacts of aviation within the CLEAN SKY target. Research and development needs to be continued in order to understand the fundamental issues affecting the performance of these material systems. Life Cycle Assessment needs to be intensified in order to further reduce ecological impacts using bio-based materials with suitable technologies to improve their properties.
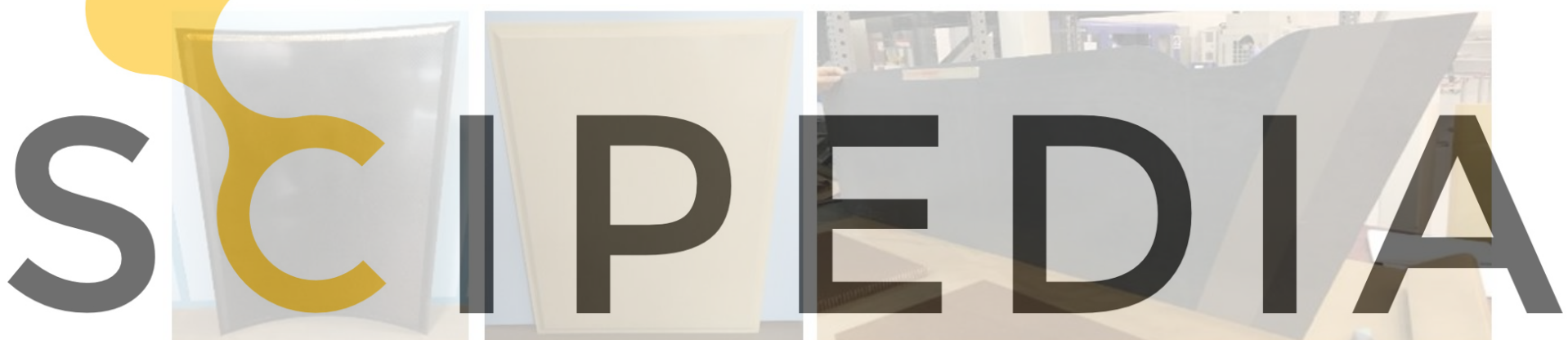

Register for free at https//www.scipedia.com to download the version without the watermark

Figure 1: Examples of demonstrators from ECO-COMPASS Project: Generic secondary (a) and interior (b) sandwich panels with Green Honeycomb core; trailing edge panel of a horizontal tail made of carbon fibre with epoxy including rosin-based curing agent (c).

\section{AKNOWLEDGEMENT}

This project was supported by the European Union's Horizon 2020 research and innovation programme (Grant No. 690638), and the Ministry for Industry and Information of the People's Republic of China (Grant No. [2016]92).

\section{REFERENCES}

[1] Bachmann J, Yi X, Gong H, et al. Outlook on ecologically improved composites for aviation interior and secondary structures. CEAS Aeronaut J (2018) 9: 533-543.

[2] Ramon E, Sguazzo C, Moreira PMGP. A Review of Recent Research on Bio-Based Epoxy Systems for Engineering Applications and Potentialities in the Aviation Sector. Aerospace. 2018; 5(4):110.

[3] Li C, Liu X, Zhu J, Zhang C, Guo J. Synthesis, Characterization of a Rosin-based Epoxy 
Monomer and its Comparison with a Petroleum-based Counterpart, Journal of Macromolecular Science, Part A: Pure and Applied Chemistry, (2013) 50, 321-329

[4] Ma S, Liu X, Jiang Y, Tang Z, Zhang C, Zhu J. Bio-based epoxy resin from itaconic acid and its thermosets cured with anhydride and comonomers, Green Chemistry, 2013, 15, 245-254

[5] Dai J, Peng Y, Teng N, Liu Y, Liu C, Shen X, Mahmud S, Zhu J, Liu X. High-Performing and Fire-Resistant Biobased Epoxy Resin from Renewable Sources, ACS Sustainable Chemistry and Engineering 2018, 6, 7589-7599

[6] Yi X, Zhang X, Ding F, Tong J. Development of Bio-Sourced Epoxies for BioComposites. Aerospace, 2018; 5(2):65

[7] Zhang J, Shen Y, Jiang B, Li Y. Sound Absorption Characterization of Natural Materials and Sandwich Structure Composites. Aerospace, 2018; 5(3):75.

[8] Wang H, Xian G, Li H, Grafting of nano-TiO2 onto flax fibers and the enhancement of the mechanical properties of the flax fiber and flax fiber/epoxy composite, Composites Part A-Applied Science and Manufacturing 76 (2015) 172-180.

[9] Li Y, Yi X, Yu T, Xian G, An overview of structural-functional-integrated composites based on the hierarchical microstructures of plant fibers, Advanced Composites and Hybrid Materials, June 2018, 1(2), 231-246

[10] Fischer, H. \& Schmid, H.G. (2013). Quality control for recycled carbon fibres. Polymers $11 / 2013$, pp. 88-91

[11] Tse B, Yu X. Gong H, Soutis C. Flexural Properties of Wet-Laid Hybrid Nonwoven Recycled Carbon and Flax Fibre Composites in Poly2018; 5(4):120.

[12] Bachmann, J. and Wied Composites Reinforced Fibres. Aerospade, 2018;5(4):107
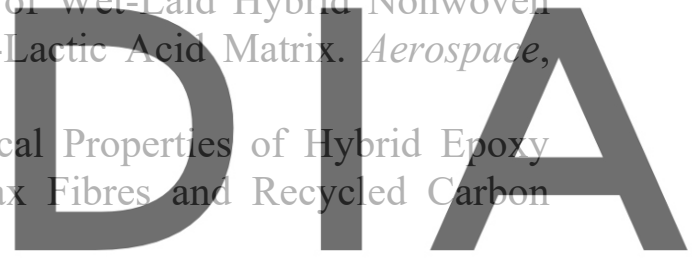

[13] Otero, F., Martinez, X., Oller, S., Salomón, S. (2015). An efficient multi-scale method for

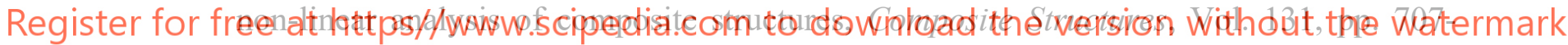
719.

[14] Lee, D.S., Morillo, G., Bugeda, G., Oller, S.,Onate, E. (2013). Robust design optimisation of advance hybrid (fiber-metal) composite structures, Composite Structures, Volume 99, 2013, Pages 181-192. ISSN: 0263-8223

[15] Tserpes K, Kora C. A Multi-Scale Modeling Approach for Simulating Crack Sensing in Polymer Fibrous Composites Using Electrically Conductive Carbon Nanotube Networks. Part II: Meso- and Macro-Scale Analyses. Aerospace, 2018; 5(4):106.

[16] Lin, YE. Functionalized interleaf technology in carbon-fibre-reinforced composites for aircraft applications. National Science Review, 2014, 01, 00: 1-2, 2013. doi: 10.1093/nsr/nwt005.

[17] Guo, Y L, Dong Q, Chen J L, et al. Comparison between temperature and pyrolysis dependent models to evaluate the lightning strike damage of carbon fiber composite laminates. Comp Part A-Appl S, 2017, 97: 10-18. 